\title{
Influence of the Damping System on the Vehicle Vibrations
}

\author{
Martin Svoboda ${ }^{1}$, Václav Schmid ${ }^{1}$, Milan Sapieta ${ }^{2}$, Karel Jelen $^{3}$, František Lopot ${ }^{3}$ \\ ${ }^{1}$ Faculty of Mechanical Engineering, Jan Evangelista Purkyně University in Ústí nad Labem, Na Okraji 1001, Czech \\ Republic, E-mail: martin.svoboda@ujep.cz vaclav.schmid@renault.cz \\ ${ }^{2}$ Faculty of Mechanical Engineering, University in Žilina, Slovakia, E-mail: milan.sapieta@fstroj.uniza.sk \\ ${ }^{3}$ Faculty of Physical Education and Sport, Charles University in Prague, José Martího 31, Praha 6, Czech Republic, E- \\ mail: jelen@ftvs.cuni.cz, flopot@seznam.cz
}

\begin{abstract}
The aim of the work was to evaluate the whole system of the springs of a passenger car. The influence of inflation and the type of tires on the acceleration of the various parts of the car (axle, steering wheel, driver's seat attachment, body shell and acceleration affecting the driver) was investigated. The types of shock absorbers and springs of the passenger car were also examined. The sensors used acceleration and pressure sensors between the wheel and the road using test stands. The benefits and reserves of the individual systems were compared, and in the systems with the cushioning rigidity, all the suspension setups were evaluated. The work was done experimentally in laboratory environment as well as in real operation.
\end{abstract}

Keywords: mechanical system, oscillation, experiment, vehicle

\section{Introduction}

The aim of this work was to assess the spring system of a personal car. The impact of inflating tires, types of tires, springs and shock absorbers were assessed on the vehicle. The required data was obtained by measuring the acceleration of the various parts of the vehicle (axle, steering wheel, driver's seat, body shell and acceleration affecting a driver) by acceleration and pressure sensors between the wheel and the road using test benches for shock absorbers based on the methods: EUSAMA and CAP.

The influence of the vehicle's spring system must be assessed in a comprehensive way in order to achieve all the goals we set on the spring system. In practice, this means above all achieving the optimum setting of suspension stiffness, choice between stiffer suspension (higher driving safety) and softer suspension (better driving comfort). The technical aspect was the assessment of the space required for installation by the system, energy intensity and reliability. The economical point of view is the substantial price of the system, the cost of maintenance and the lifetime.

The issue of damping and determining the required properties of shock absorbers and springs in passenger cars is directly related to the efforts of motor vehicle engineers to increase the comfort of the vehicle crew and, above all, the road traffic safety. The aim is also to reduce the negative impact of the vibration transfer on other parts of the vehicle, thus increasing the wear and reduction of their service life. [1-3].

From the technical point of view, it is necessary to assess the space required for system installation, energy performance and reliability. From an economic point of view, the price of the system, the cost of maintenance and the service life are very essential.

When a vehicle crosses something uneven, an instant reaction of a damping system and a change of shock absorbers' attribute from soft-convenient for a crew com- fort, to hard - convenient for faster damping by suppressing the undesirable form of oscillation, are required.

Driving comfort is from the physical point of view the acceleration of the superstructure, which acts on the crew of the car and especially the driver. In particular, driving safety is the dynamic forces between the wheel and the road, resulting in tire pressure on the road / tire bounce from the road, whereby the wheel must always be in contact with the road, even when driving over bumps. It is not possible to assess ride safety and ride comfort separately, it is always necessary to ensure safe driving with regard to acceptable driving comfort.

With the passive system, fast reaction of the damping system is not ensured when crossing unevenness and the shock absorbers' characteristics is changed from soft to hard, with faster attenuation by suppression of the undesirable vibration shapes. The solution is the use of adaptive dampers or parametric dampers. It achieves significantly better results than passive damping. However, it is not possible to talk about optimal system setup. The best solution for comfortable ride and maintaining a constant value of wheel-to-ground load is the active springing system. The ideal wheel-to-ground load value is the static load value. Active systems capture the load on the wheels and measure the distance between the wheel axle and the shock absorber body (measurement of the change in vehicle height).

The type of axle used (rigid axle, rigid semi-suspension, independent suspension of the wheels) has a crucial effect on damping and that is due to the principle of construction itself (axles, arms, articulated joints, stabilizers, etc.) and due to damping, which was used (leaf springs, helical/coil springs, McPherson springs, torsion bars, rubber springs, air springs, bellows etc.). Regarding axles the design has an effect on the size of the unsprung masses. The objective of the vehicle design should be to reduce as much as possible the unsprung masses, or to constructively ensure the transfer of these masses into the area of the sprung masses [7-10].

From the point of view of the crew comfort, it is also 
important to look into suspension and ergonomics of the seats. For seats, the most carriers use a metal support frame with tensioned elastic wire reinforcement on which a seat and backrest of flexible PUR foam [4 - 8] are attached.

Suspension system has the task of capturing shocks from the roadway (resulting from obstacle crossing or wheel bump due to road unevenness, altering bumps to oscillation and reducing oscillation by damping. When the wheel is moving, it compresses or extends the spring. When crossing the obstacle, the spring accelerates the movement of the body (spring compression) by its force, and consequently blocks the movement of the body (spring extension). The compression and stretching of the spring takes place around the rest position, until the complete attenuation, i.e. the conversion of the kinetic energy into the thermal, occurs. The springs (and the shock absorbers) are located between the suspension of the wheels and the superstructure (body). Suspension ensures that the vehicle is a "oscillating system" with its own body frequency, which is defined primarily by the size of the unsprung mass of the vehicle and the characteristics of the springs.

The characteristic is defined by the spring stiffness $\mathrm{c}$ $\left[\mathrm{N} . \mathrm{m}^{-1}\right]$, which is defined by the ratio of force $\mathrm{F}[\mathrm{N}]$ to the path $\mathrm{s}$ [m]. The pattern may be linear or progressive, soft to 60 oscillations per minute has a negative impact on nausea, or hard above 90 oscillations per minute has impact on spine shock $[1,2]$

When constructing the damping system, it is necessary to consider the operating conditions and calculate them and then design the suspension parameters. For all calculations, a simplified dynamic model with appropriate degrees of freedom is used (most often with two), see Fig. 1.

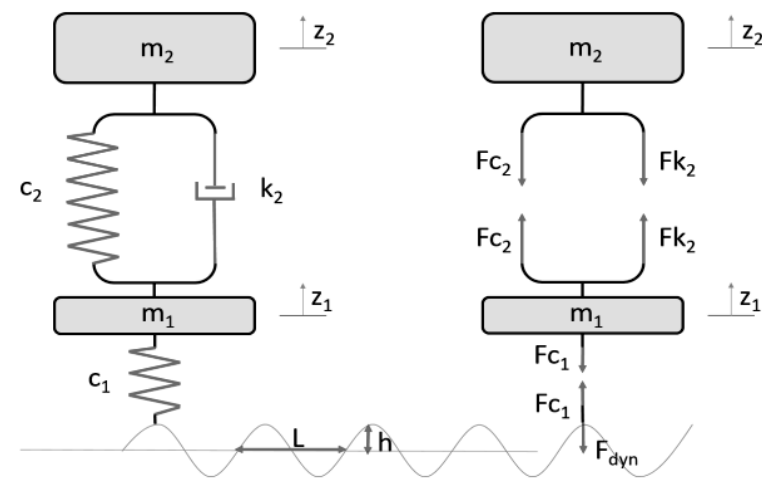

Fig. 1 Dynamic damping model [3]

Legend to the Fig.1:

$m_{1}[\mathrm{~kg}] \quad$ - mass of the unsprung mass (wheels and the part of wheel suspension)

$m_{2}[\mathrm{~kg}] \quad$ - mass of the unsprung mass (superstructures, car body including loads and crew)

$c_{1}[\mathrm{~N} / \mathrm{m}] \quad$ - radial tire stiffness

$c_{2}[\mathrm{~N} / \mathrm{m}] \quad$ - stiffness of the spring

$k_{1}[\mathrm{Ns} / \mathrm{m}] \quad$ - coefficient of linear acceleration

$F_{c}, F_{k}[\mathrm{~N}] \quad$ - forces of an unstrung system

$F_{d y n}[\mathrm{~N}] \quad-$ dynamic road force

$L[\mathrm{~m}] \quad$ - wavelength at periodic oscillations

$h[\mathrm{~m}] \quad$ - amplitude height
An important damping element is tire. For tires, the prescribed tire size and tire pressure must be observed. The use of tires with a different mixture for summer and winter traffic (hardening of the summer mixture in the winter season and too soft tread for winter tires in the summer) is also very important. The difference is also in the radial tire stiffness, expressed more often as the subtangle of tires, especially in the case of structurally different radial and diagonal tires. For passenger cars, almost exclusively radial construction is used.

Transmission of vibrations into the steering wheel through the steering system (vibration from the wheels through the steering link on the transmission and further through the steering wheel) but also the vibration damping (and silencing) of the body using reinforcement and fillers.

Numerous other elements of the vehicle, which influence directly or indirectly damping and vibration, can be mentioned. In designing, the experience and knowledge of designers, technologists and material engineers and their cooperation to find the optimal solution in the field are of great impact.

\section{Methodology and measurement results}

The paper deals with tire adhesion to the road in terms of tire stiffness, vehicle load and tire inflation. The measurements were made using the EUSAMA methodology on chassis tester. Vertical acceleration (hoist) was measured at the same time on different parts of the vehicle. Part of the measurement was also a statistical survey of the state of the shock absorbers of a random sample of vehicles.

When crossing an uneven road by a vehicle, there is necessary for damping system to react promptly and the change of the characteristics of shock absorbers from soft-convenient for the crew comfort - to hard, which is convenient for faster damping by suppressing the undesirable form of oscillations (see Fig. 2). Such a solution is used in adaptive dampers or parametric ones.

By means of the acceleration sensors LIS331DL STMicroelectronics acceleration values of the various operating states were measured and subsequently evaluated. The sensors were placed on the chassis, the car body and also in the interior of the vehicle. They were placed on the driver's seat and on the steering wheel.

The following was measured:

- adhesion of tires to the road depending on the vehicle's driving mode with varying stiffness and acceleration on the chassis, body, steering wheel and mount of the driver's seat.

- adhesion of tires to the road depending on load and acceleration on the steering wheel and mount of the driver's seat

- adhesion of tires to the road depending on tire inflation and acceleration on the mount of the driver's seat

- statistical measurement of damper condition

- acceleration on the mount of the driver's seat when crossing unevenness on the test path. 


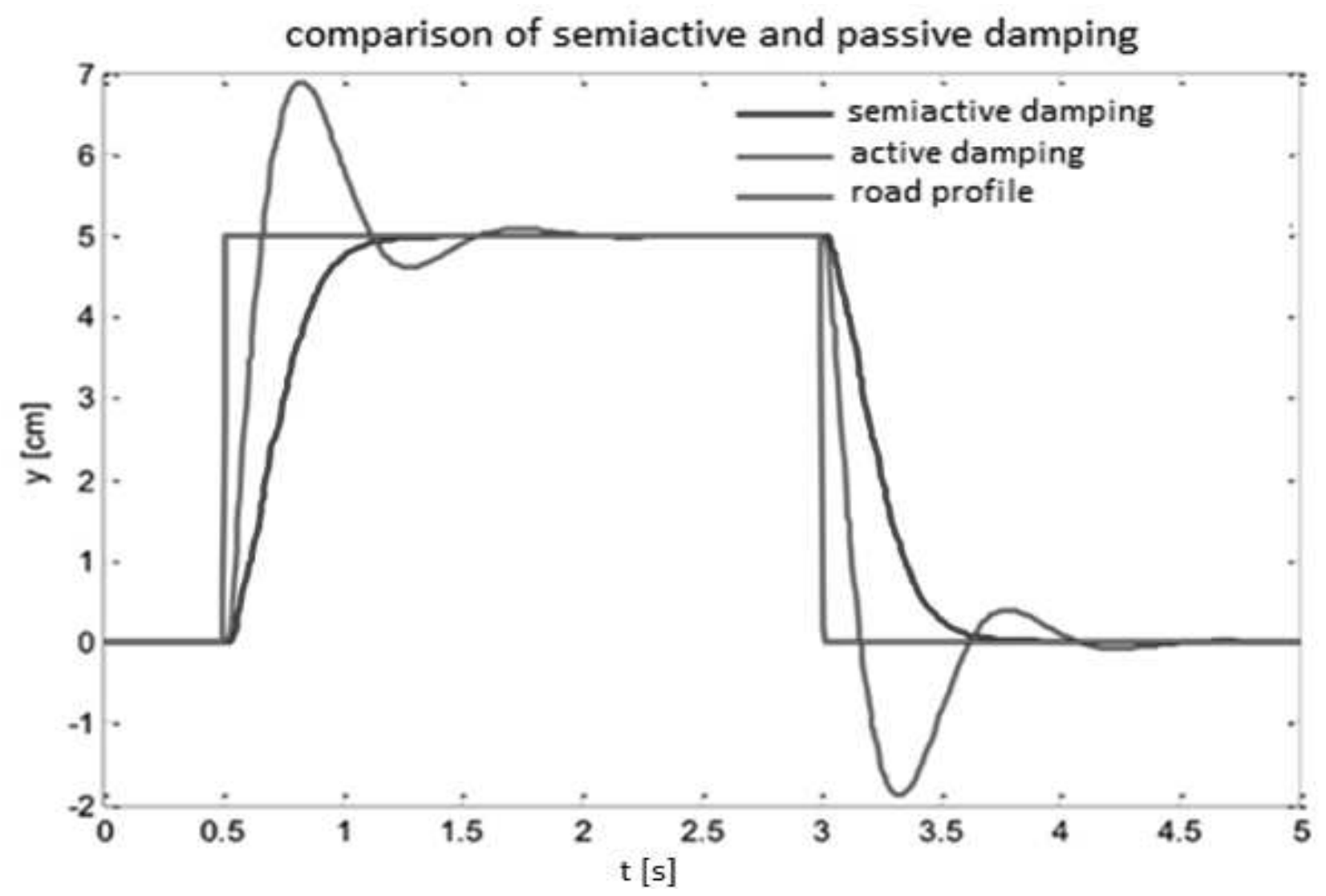

Fig. 2 Comparison of the process of damping for rectangular profile - simulation in Matlab

Tire acceleration and tire adhesion (damping) measurements were performed on the test bench of the shock absorbers, as well as the tire pressure was measured by the EUSAMA method. The ratio of the minimal dynamic force of the wheel to the static force was measured. During the test, both the percentage ratio of these forces was measured and the forces on the left and right sides of one axle were compared. Measurements were made on vehicles equipped with passive damping and adaptive damping. For vehicles with an adjustable system, all shock absorber states were measured. Tire adhesion measurements were made to the road and vibration transmission to different vehicle parts depending on the damper stiffness (soft, medium and hard settings). Fig. 3 shows the position of the acceleration sensors on the front axle.
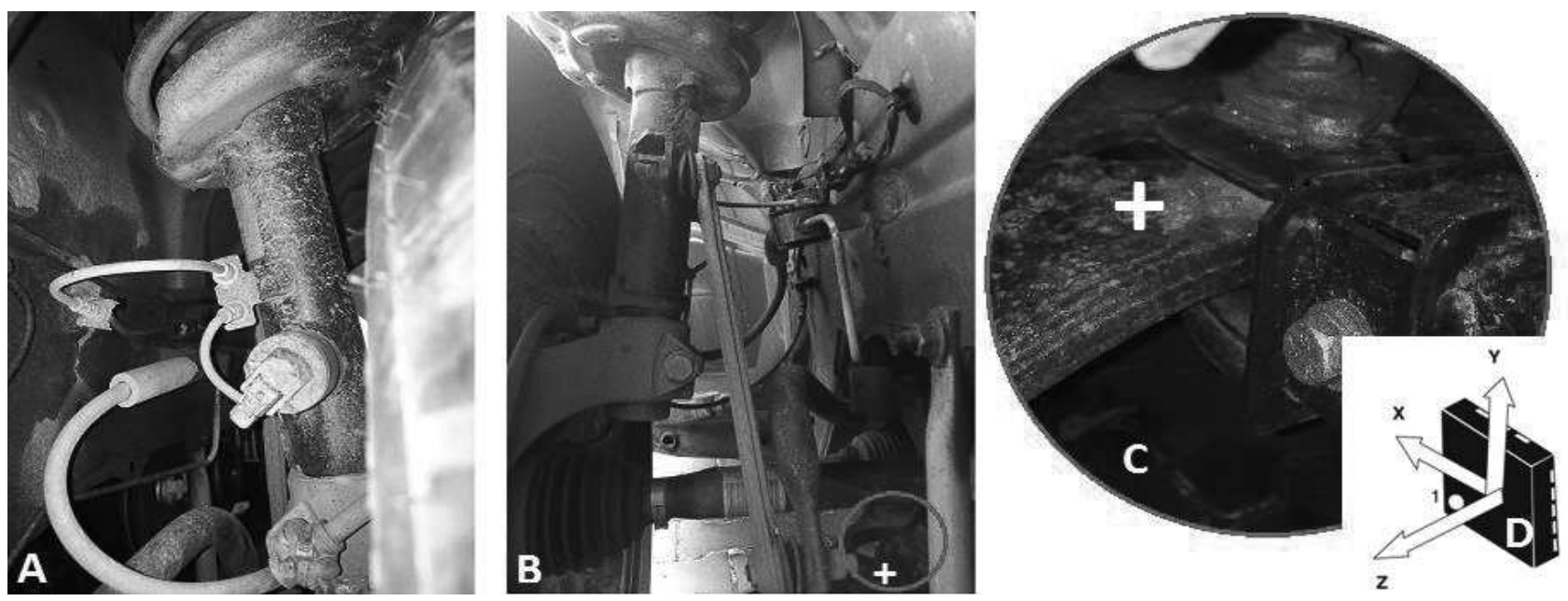

Fig. 3 Position of the acceleration sensor on the front axle

Legend to the Fig.3:

A- damper with variable-effect, $B$ and $C$ - sensor position (marked with a cross)

$D$ - Directions of acceleration sensor measurements

The vehicle was excited in different variants (Table 1). 
Tab. 1 Variations of acceleration measurements performed on the vehicle

\begin{tabular}{|c|c|c|c|c|}
\hline & seat sensor & steering wheel sensor & sensor axle & body sensor \\
\hline Generation 0,5 A & I & II & III & IV \\
\hline Generation 0,8 A & V & VI & VII & VIII \\
\hline Generation 1,2 A & IX & X & XI & XII \\
\hline without generation & XIII & XIV & XV & XVI \\
\hline
\end{tabular}
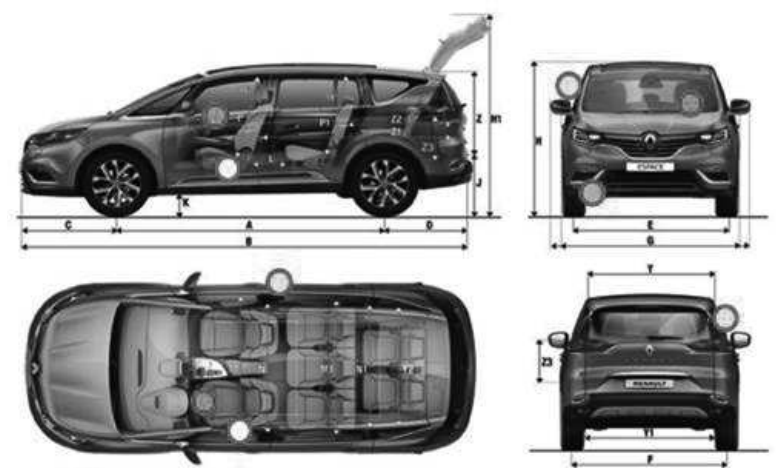

front axle - right side

center column - right side

seathandle-driver

steering wheel

Fig. 4 Location of the acceleration sensors on the Espace IV.
The sensors were located on the driver's seat, steering wheel, centre pillar on the right side of the car body and on the right side of the front axle (Fig. 4.). Before starting the measurement, it was necessary to check whether the sensor was correctly positioned in all three axes $X, Y, Z$.

Measurement with variable stiffness of shock absorbers: Generation - 0.5A - Comfort and Normal driving mode, with generation 0.8A - Sport mode, with generation 1.2A - "Repair" mode for braking, acceleration and quick rotation of the steering wheel and without generation - Fault mode when emergency. The variable damping system on the Espace IV vehicle is solved by a TENNECO electromagnetic valve (Fig. 5), which is inserted into bypass channels, thereby changing the amount of oil filling above and below the piston and thereby passing the oil through the holes in the piston. The diagram of the layout of the modules involved in the measurement, evaluation and adjustment of the stiffness of the shock absorbers is shown in Fig. 6.

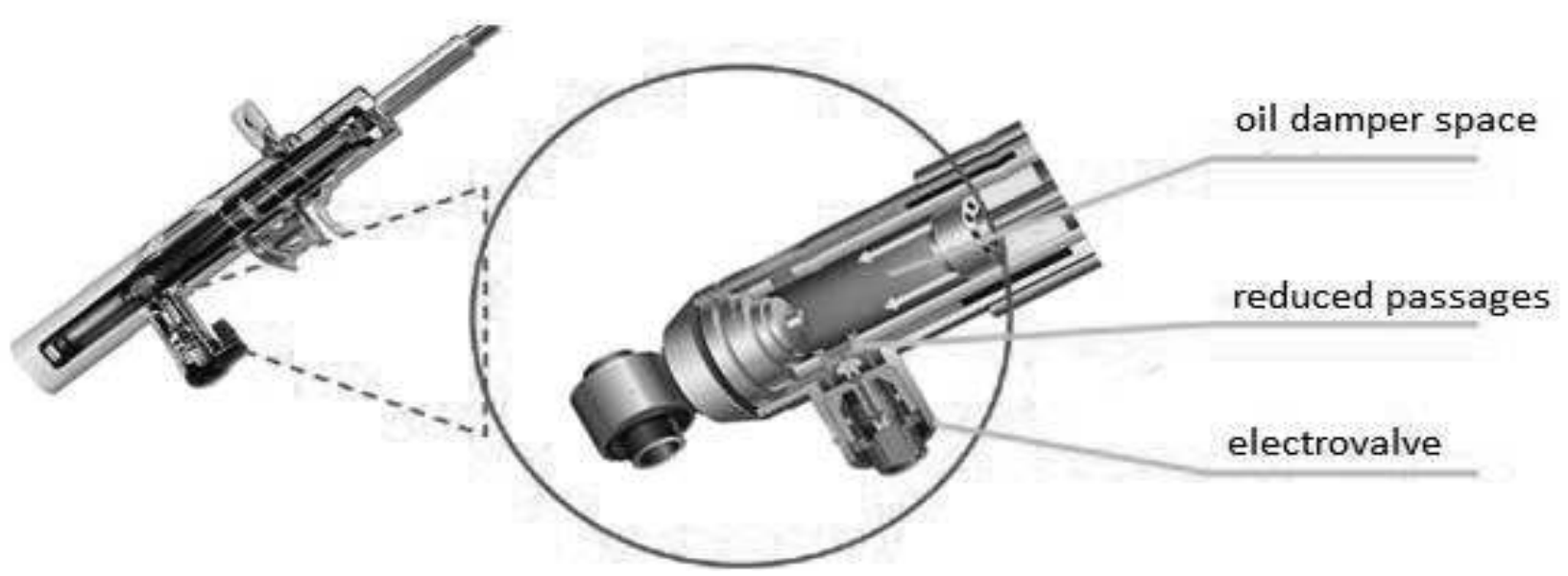

Fig. 5 Diagram of location and principle of the variable damping electrovalve [3]

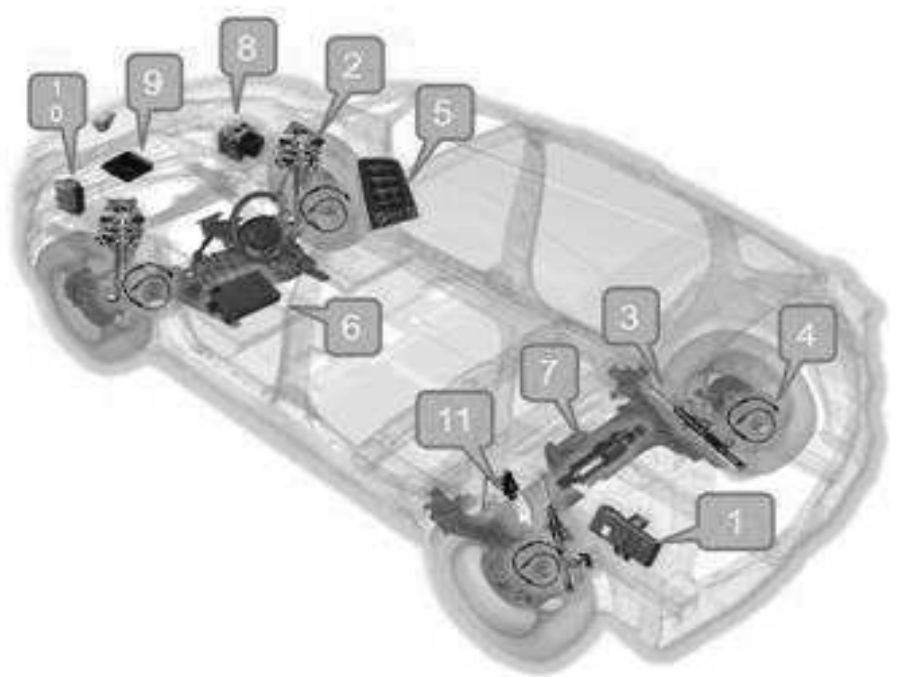

1 - ECU dampers

2 - front shock absorbers

3 - rear dampers

4 - steering cable

5 - multifunction control display

6 - UCE cabins

7 - wheel UCE

8 - URCE ABR / ESP

9 - protection and communication unit

10 - injection UCE

11 - rear Height Sensor

Fig. 6 Diagram of location and principle of damping units [3] 


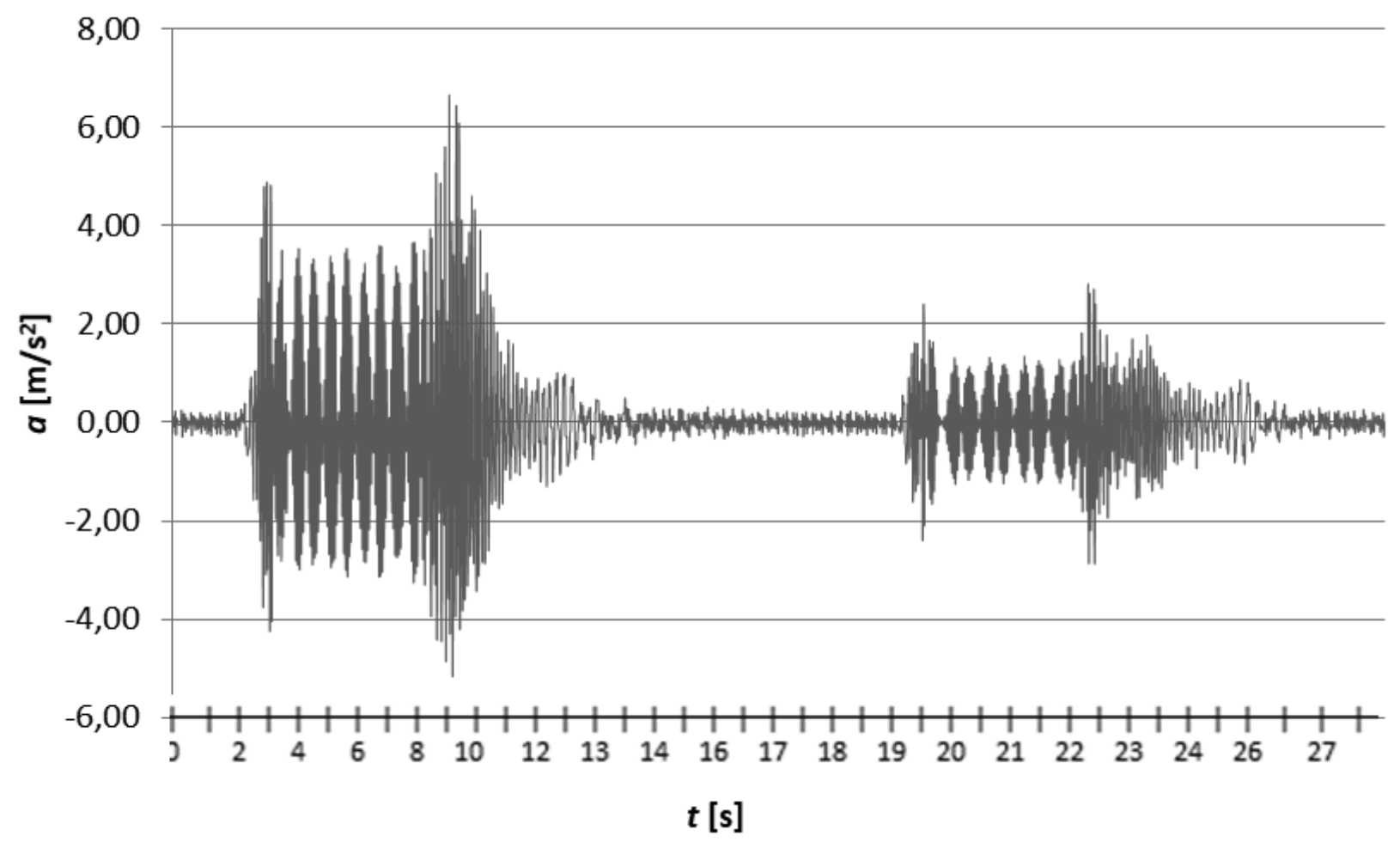

Fig. 7 Acceleration Course on Driver Seat Mount in Braking Mode - Measurement No. IX

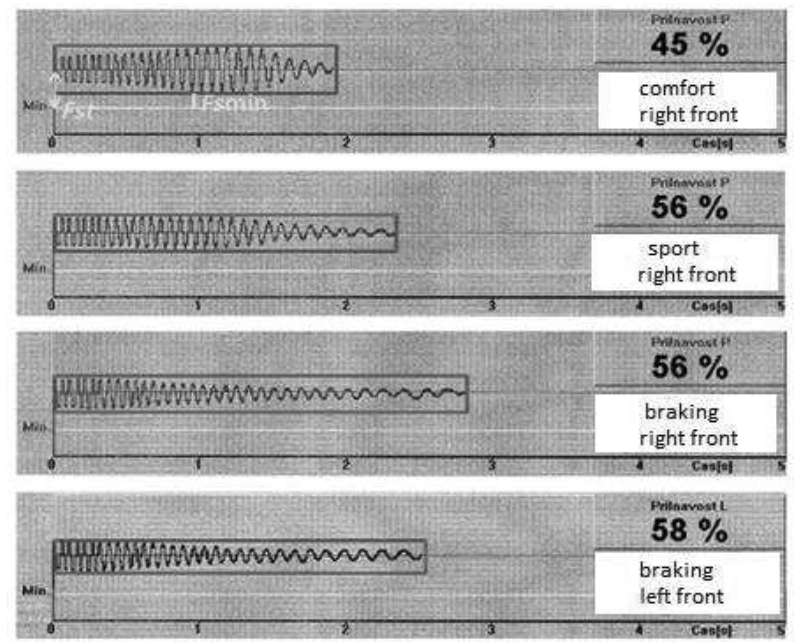

Fig. 8 Comparison of LINE chassis screen test for individual shock absorber modes

The compressive force in comfort mode is noticeably smaller than in sport mode. This corresponds to the theoretical assumption for passive shock absorbers that they are set to the compromise between safety and convenience. In comfort mode, greater comfort is preferred, as can be seen from the vibration chart 4.2.11, where the maximum acceleration measured on the driver's seat mount is only $3.07 \mathrm{~m} . \mathrm{s}^{-2}$, at a pressure of $45 \%$.

The pressure force in comfort mode is noticeably smaller than in sport mode. This corresponds to the theoretical assumption for passive dampers that the damper is set to a compromise between safety and comfort. In the case of comfort mode, greater comfort is preferred, where the maximum acceleration measured at the driver's seat is only $3.07 \mathrm{~m} . \mathrm{s}^{-2}$, at a pressure of $45 \%$.

The evaluation values of the compressive force according to the EUSAMA methodology are:

- above $60 \%$ excellent

- $41-60 \%$ good

- $21-40 \%$ satisfactory

- $1-20 \%$ unsatisfactory

- $0 \%$ non-functioning

Table 2 shows the results of the tire pressure measurement.

Tab. 2 Front wheel axle pressures at different stiffness of the shock absorbers, average 10 measurements

\begin{tabular}{|c|c|c|c|}
\hline & Front left wheel pressure & Front right wheel pressure & difference in adhesion \\
\hline Generation 0,5 A & $\mathbf{4 6 . 3} \%$ & $\mathbf{4 4 . 1} \%$ & $\mathbf{2 . 2} \%$ \\
\hline Generation 0,8 A & $\mathbf{5 5 . 8} \%$ & $\mathbf{5 5 . 7} \%$ & $\mathbf{0 . 1} \%$ \\
\hline Generation1,2 A & $\mathbf{5 6 . 9} \%$ & $\mathbf{5 3 . 5} \%$ & $\mathbf{3 . 4 \%}$ \\
\hline Without generation & $\mathbf{5 7 . 2} \%$ & $\mathbf{5 7 . 3} \%$ & $\mathbf{0 . 1} \%$ \\
\hline
\end{tabular}


According to the EUSTANA methodology, all shock absorbers condition measurements are in the second area where $41-60 \%$, i.e. in the area marked as good condition of the shock absorbers. For vibration transfer to the steering wheel, the maximum acceleration value is around 1 $\mathrm{m} . \mathrm{s}^{-2}$, but the transmitted vibration is shaped differently from the seat mount (Fig. 9 and 10).

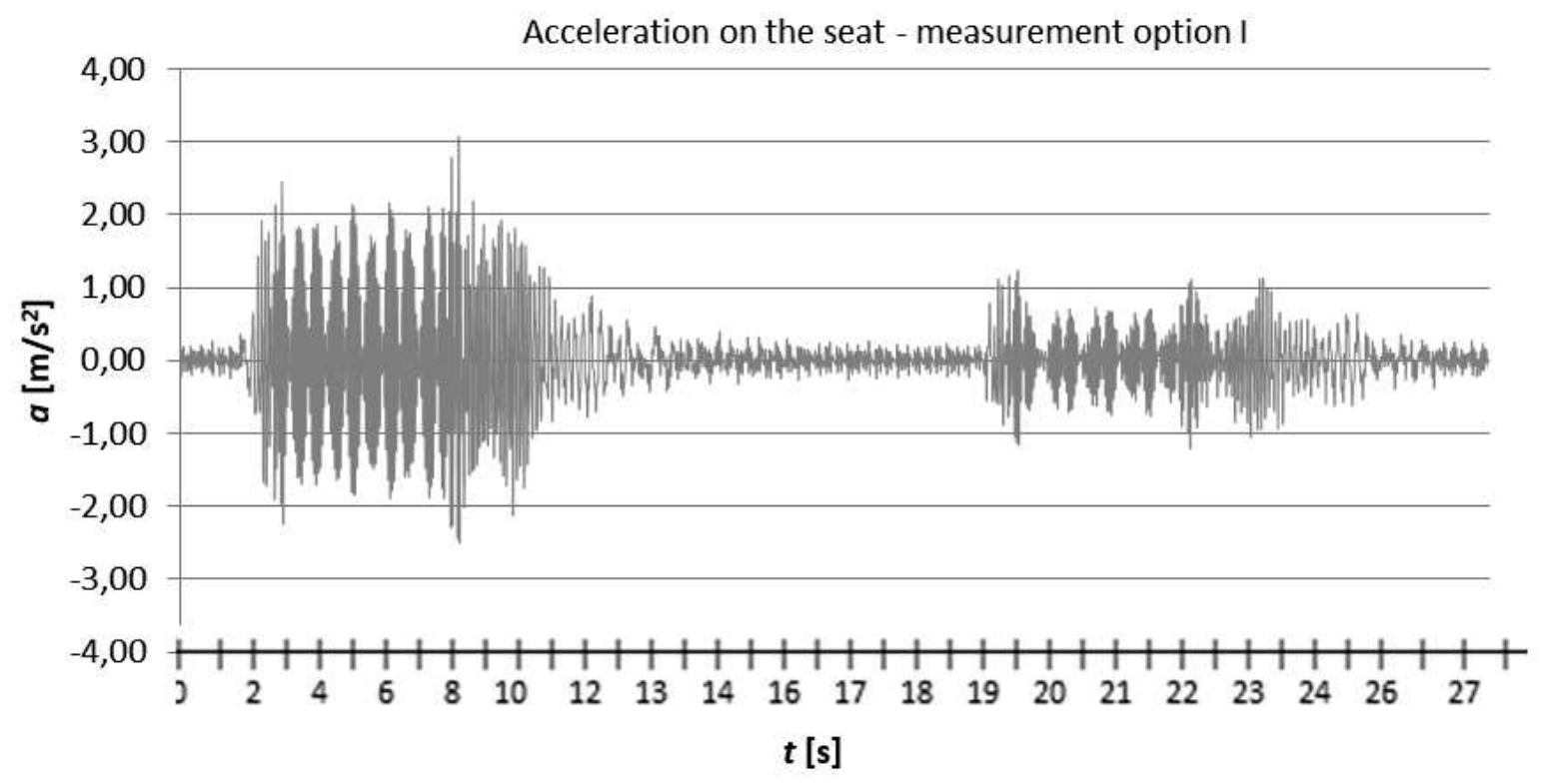

Fig. 9 The process of acceleration of the seat mount for the left and right wheel of the front axle in comfort mode.

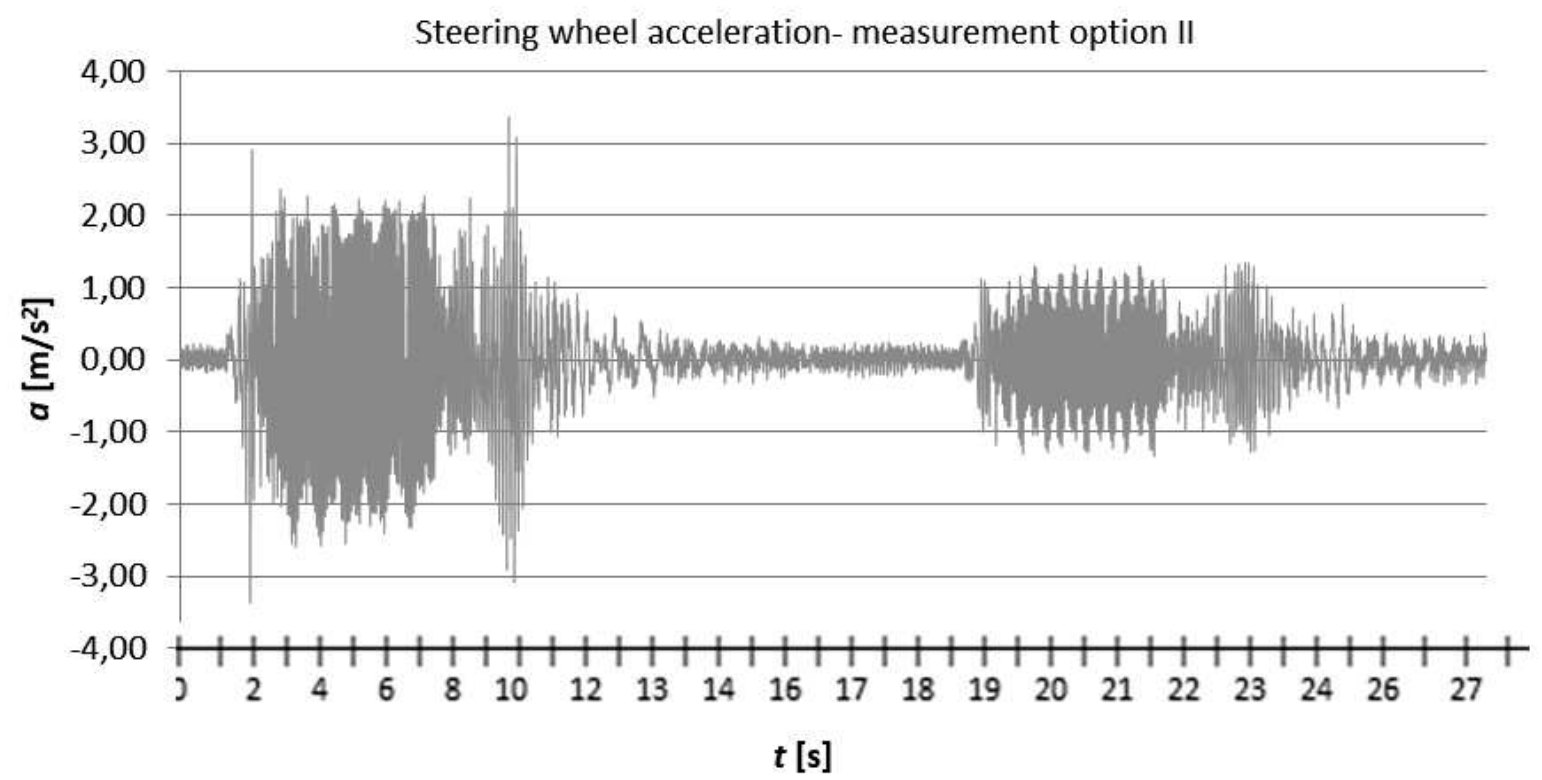

Fig. 10 The acceleration action on the steering wheel for the left and right wheel of the front axle in comfort mode.

\section{Conclusion}

The objective of the measurement was to determine the reaction of the damping system to the various operating conditions of the tested passenger cars. All measurements made with the help of tester chassis and test drive were performed to reveal the possible impacts of operating conditions in particular on crew comfort and driving safety.

By measuring, the theoretical assumption was made that the amount of vibration transmission to different parts of the vehicle depends on the amount and type of connection between the wheel and the measured part of the vehicle. The type of connection disadvantageous for vibration transmission is fixed (usually spot welded on the vehicle) and glued. This is visible in the transmission of vibrations to the post. Conversely, the advantageous connections for vibration transmission are flexible connections (seat cushion placed on a flexible metal structure, various types of joints of articulated, sliding, rack gears, ie, for example, classic steering transmission, pneumatic, hydraulic, and so on. their distance from the source of vibration.

Tire adhesion to the road was measured at different 
damping stiffnesses. By measuring, the theoretical assumption was found that manufacturers are addressing damping as a compromise between safety and comfort (accelerating on the crew). Soft damping has a 20\% lower maximum acceleration value, but at the same time $20 \%$ less downforce than in hard mode. We do not get even out of acceptable values for one measurement. We would appreciate the difference in pressure setting in extreme situations, ie fast driving on poor quality surfaces in sports cars, regardless of the impact of higher vibrations on the crew. In conventional vehicles, a softer setting is preferable, which is more comfortable for the crew and safer for loads when driving over unevenness. The function of the automatic hard mode, which is activated when braking, accelerating or cornering quickly, is the most meaningful for the vehicle being measured.

\section{Acknowledgment}

The article was created with the contribution of SGS Grant support - Jan Evangelista Purkyně University in Ústí nad Labem and by grant UJEP-IGA-TC-2019-4804-2

\section{References}

[1] VLK, F. (2003). Dynamics of motor vehicles, nakladatelství a vydavatelství, Brno 2003, ISBN: 8023900242

[2] VLK, F. (2001). Tasks of motor vehicle dynamics, BRNO, 2001 ISBN 8023865749

[3] Interní materiál Renault, AMORTISSEMENT PILOTE, Renault S.A. 2015
[4] DIŽO, J., BLATNICKÝ, M., SKOČILASOVÁ, B. (2015). Computational modelling of the rail vehicle multibody system including flexible bodies. In: Communications: scientific letters of the University of Zilina. Vol. 17, Issue 3, 2015, p. 31-36. ISSN 1335-4205. Registered in Scopus.

[5] SAPIETA, M., DEKYS, V., STEVKA, O. (2013). Localization Lüders band in infrared spectrum. In: Applied Mechanics and Materials. - Vol. 420, p. 194-201, 2013, ISSN 1660-9336

[6] SEGL'A Š., OREČNÝ M., TRIŠOVIĆ N. (2013). Semiactive seat suspension with a vibration absorber - 2013. In: Manufacturing Technology. Vol. 13, no. 4 (2013), p. 534-539. - ISSN 1213-2489

[7] SAPIETA, M., DEKYS, V., STEVKA, O. (2013). Localization Lüders band in infrared spectrum. In: Applied Mechanics and Materials. - Vol. 420, p. 194-201, 2013, ISSN 1660-9336

[8] SEGLA Š., OREČNÝ M., TRIŠOVIĆ N. (2013). Semiactive seat suspension with a vibration absorber. In: Manufacturing Technology. Vol. 13, no. 4 (2013), p. 534-539. - ISSN 1213-2489

[9] SAPIETA, M., SVOBODA (2019). Strength Computation of Bearing Test Station, In: Manufacturing Technology, Vol. 19, No. 5 (2019) pp. 842-847, ISSN: 1213-2489

[10] SEGLA, Š., KAMPO, J. (2018). The Role of Modelling of Road Unevennesses in Vehicle Dynamics, In: Manufacturing Technology, Vol. 18, No. 1 (2018) pp. 124-129, ISSN: 1213-2489 